\title{
What drives interdependence of FDI among host countries? The role of geographic proximity and similarity in public debt is
}

\author{
Luisa Alamá-Sabater ${ }^{\mathrm{a}, 1,2}$, Benedikt Heid ${ }^{\mathrm{b}}$, Eduardo Jiménez-Fernández ${ }^{\mathrm{c}, 1,3}$, Laura Márquez-Ramos ${ }^{\mathrm{d}, *, 1,4}$ \\ a Universitat Jaume I and Local Development Institute (IIDL), Spain \\ ${ }^{\mathrm{b}}$ University of Bayreuth and CESifo, Faculty of Law, Business Management and Economics, Universitätsstraße 30, 95447 Bayreuth, Germany \\ c Universitat Jaume I, Spain \\ ${ }^{\mathrm{d}}$ Universitat Jaume I and Institute of International Economics (IEI), Spain
}

\section{A R T I C L E I N F O}

\section{Article history:}

28 December 2015

27 May 2016

Accepted 15 June 2016

Available online $\mathrm{xxxx}$

\section{JEL classification:}

F21

F42

F44

F45

\section{Keywords:}

Foreign direct investment

Financial contagion

Spatial econometrics

Fuzzy metrics

Public debt

Maastricht Treaty

\begin{abstract}
A B S T R A C T
We investigate the drivers of interdependence between flows of foreign direct investment (FDI), focusing on two potential channels: interdependence between geographically close FDI destination countries, and between destination countries with similar levels of public debt. Using data on bilateral FDI flows between the 27 EU member countries in 2007, we find that in addition to geographic proximity, similarity in public debt levels drives cross-country correlation in FDI inflows. The public debt threshold of 60\% of GDP prescribed by the Maastricht Treaty is a crucial driver of interdependence between FDI inflows. FDI inflows are correlated within the group of compliant countries as well as within the group of non-compliers. This is consistent with the fact that foreign investors distinguish between countries which violate this Maastricht criterion and those that do not.
\end{abstract}

(c) 2016 Elsevier B.V. All rights reserved.

\section{Introduction}

Across-market spillovers or spatial interdependence in financial flows such as foreign direct investment (FDI) have become a key concern for academic scholars. This paper contributes to this literature by distinguishing two channels for interdependence of bilateral FDI flows between neighboring FDI destination countries. Previous studies have highlighted

\footnotetext{
is We thank the editor as well as an anonymous referee for their useful comments.

* Corresponding author

E-mail addresses: luisa.alama@uji.es (L. Alamá-Sabater), benedikt.heid@uni-bayreuth.de (B. Heid),jimeneze@uji.es (E. Jiménez-Fernández), Imarquez@uji.es (L. Márquez-Ramos).

1 Address: Department of Economics, Universitat Jaume I, Campus del Riu Sec, 12071, Castellón de la Plana, Spain.

2 Supported by grant ECO2014-55221-P of the Ministerio de Economia y Competitividad (Spain) and Universitat Jaume I (P1-1B2013-06).

${ }^{3}$ Supported by grant MTM2012-36740-C02-02 of the Ministerio de Economía y Competitividad (Spain).

4 This author acknowledges the support by Universitat Jaume I (P1-1B2013-06) and Generalitat Valenciana (PROMETEOII/2014/053).
}

geographic proximity as a channel that gives rise to interdependence of investments across FDI host countries (e.g., Baltagi et al., 2007; Blonigen et al., 2007): investments made by one source country in different host countries which share a common border or which are geographically close are correlated. This paper focuses on a new channel for interdependence of FDI: FDI flows are correlated across host countries with similar levels of public debt.

During the recent financial crisis and subsequent public debt crisis in the European Union (EU), many observers feared that an economic downturn in one country could spill over to other countries. However, the fear was not about "contagion" across geographically close countries but across countries with similarly high debt levels. ${ }^{5}$ Accordingly, some analysts, economists, and the press pejoratively referred to Portugal,

\footnotetext{
5 There are numerous articles about this in the press. A typical example is an article in the "Financial Times" on 04/29/2010 with the title "Spanish debt downgrade by S\&P sparks fresh fears over contagion as euro suffers" which cites the then head of the Organisation for Economic Co-operation and Development, Angel Gurria, with the words "It's not a question of the danger of contagion; contagion has already happened". And further, "This is like Ebola. When you realise you have it you have to cut your leg off in order to survive".
} 
Italy, Greece, and Spain as the "PIGS" countries to highlight their similar macroeconomic characteristics, such as their high levels of public debt. ${ }^{6}$ Fig. 1 depicts the ratio of central government debt to GDP in the EU in 2007. As can be seen, similarity in public debt levels does not strictly follow geographic borders but defines a distinct dimension for potential interdependence of investments between host countries.

This was one of the convergence criteria of the Maastricht Treaty which sparked the most intense debate in the media and policy arena: a country has to have a public debt-to-GDP ratio of $60 \%$ or lower. In fact, a higher level of debt is considered as a violation of the Maastricht Treaty.

Our main hypothesis is that investors perceive the Maastricht compliers and non-compliers as two separate groups of countries. Under imperfect information, when an investor is deciding on the amount of FDI in a particular country, she may use not only information about a country's business cycle (proxied by, for example, a country's GDP) but also information from other, similar countries. We argue that it may not be only between geographically close countries that this learning across countries occurs. In addition, investors may use the violation of the Maastricht criterion as an additional criterion to group countries. Hence, information which leads to a change in FDI in a country within, say, the group of Maastricht compliers may also influence FDI decisions in other countries in the same group. Accordingly, the correlation between FDI flows should be higher within groups but not between groups, i.e., it should be higher if both host countries violate the Maastricht criterion. Similarly, if two host countries are below the Maastricht threshold, they should exhibit a higher correlation of inbound FDI flows. This is also in line with investors using Maastricht compliance as a noisy signal of fiscal policy under imperfect information (see Fève and Pietrunti, 2016). Imperfect information is particularly relevant for FDI (see, e.g., Portes and Rey, 2005).

Let us explain by using a simple example. Consider an investor from country A that already invests in three countries: B, C, and D. B shares a common border with $\mathrm{C}$ but not with $\mathrm{D}$. B and $\mathrm{D}$ both have public debt-to-GDP ratios above $60 \%$ and thus are in violation of the of the Maastricht Treaty convergence criteria, while $C$ is below this level (see Fig. 2). Now, imagine that there occurs a negative shock in country $B$ which leads the investor from A to reduce her investments in B. If there are only geographic spillovers in FDI across destinations, this will lead the investor to reduce her investments in the contiguous country C but not in D. However, if the level of public debt is a relevant channel for FDI spillovers, she will reduce her investments in D but not in C. If both channels are important, she will reduce her investments in both $C$ and $D$.

A similar story could be told with three investors from $A$ who have each only a single investment in B, C, and D, respectively, and who learn from the behavior of each other. If one investor reduces her investment in B, this may lead other investors to also reduce their investment in C or D. This alternative story stresses the possibility of learning across investors within a country. Both stories have identical implications for aggregate FDI flows: FDI flows may be correlated across host countries due to either the geography or the public debt channel we propose. ${ }^{7}$

We provide evidence consistent with the channel of similarity in public debt levels, in addition to the geographic proximity channel. We do so by using a spatial gravity model of European bilateral flows of FDI in 2007, which allows us to gauge the relative importance of the two separate channels by specifying two separate spatial weight matrices. In addition, our paper introduces a simple and effective method to construct spatial weight matrices, so-called fuzzy metrics. Fuzzy

\footnotetext{
${ }^{6}$ For example, "The Sun”, a British tabloid newspaper, published a cartoon which showed four pigs eating money dressed in the flags of the four countries, as reported by http://www.englishblog.com/2010/02/cartoon-euro-pigs.html\#.VzDBqPmLQm4., accessed 05/09/2016.

7 According to the "fire-sale FDI hypothesis", negative shocks in a host country may actually increase FDI inflows, see Weitzel et al. (2014). Still, the question remains whether there exists interdependence between FDI host countries, and via which channel this interdependence operates.
}

metrics allow the researcher to model a concept of 'neighborhood' that takes several dimensions of space into account, generalizing the uni-dimensional weight matrices typically used in the spatial econometrics literature. They also allow us to construct a summary measure of the two channels of potential interdependence between host countries. Our proposed method is completely general and can be applied to other areas which use spatial econometric methods.

The remainder of the paper is structured as follows: Section 2 reviews the literature. Section 3 introduces our spatial econometric framework for modeling the interdependence of bilateral FDI flows across host countries due to both geographic proximity and similarity in public debt. Estimation results are presented in Section 4. Section 5 concludes.

\section{Literature review}

The conventional framework for studying the determinants of bilateral FDI flows has been the gravity equation, which takes into account the fact that FDI depends on origin and destination factors as well as on bilateral variables such as geographical distance between the origin and the destination of flows, as is the case with gravity regressions for bilateral trade flows. Distance is an impediment to trade due to trade costs, which partly consist of transport costs for shipping physical goods. Portes and Rey (2005) and Daude and Fratzscher (2008) argue that FDI flows decrease with increasing distance due to higher informational frictions. These frictions are a key concern for investors due to monitoring costs as well as uncertainty generated by an unknown business environment. Other examples for bilateral gravity models of FDI are de Ménil (1999), Bergstrand and Egger (2007), Márquez-Ramos (2011), and Blonigen and Piger (2014).

A second strand of the literature models the interdependence of FDI between host countries using spatial econometrics. Examples are Baltagi et al. (2007), Blonigen et al. (2007), Baltagi et al. (2008), Chou et al. (2011), Blanco (2012), Leibrecht and Riedl (2014), and Alamá-Sabater et al. (2016). In these studies, interdependence between FDI host countries arises due to geographic proximity. In econometric terms, simple dichotomous measures of neighborhood (sharing a common border or not) are used to construct the spatial lag. Also, continuous measures of neighborhood using some function of the distance between two countries have been employed. However, none of the studies consider the interdependence between FDI due to similarity in public debt across host countries as we do.

To the best of our knowledge, only Claeys et al. (2012) use somewhat similar measures to model the interdependence of interest rates between countries. They use the capitalization of the bond market (both public and private) as well as debt in terms of GDP to calculate spatial weights in their spatial econometric approach. Their results highlight the interdependence of interest rates between EU countries due to our proposed channel of public debt similarity.

Our paper also relates to the literature on macroeconomic interdependence, financial network effects, and contagion between countries, e.g., Allen and Gale (2000), Dasgupta (2004), Leitner (2005), Elliott et al. (2014), Acemoglu et al. (2015), and Babus (2016). This literature predominantly focuses on cross-border holdings of assets and debt between banks. Besides banks, mutual funds are also potential drivers of interdependence via their portfolio investments (see Puy, 2016). Financial services are an increasingly important part of FDI, as they constituted roughly $50 \%$ of the total value of cross-border mergers and acquisitions worldwide in 2007, up from about 20\% in 2002, see Buch and Lipponer (2007) and UNCTAD (2008).

It is worth mentioning that there is no broad consensus as to what constitutes contagion. For a recent overview of the different definitions used, see Gómez-Puig and Sosvilla-Rivero (2016). For example, Forbes and Rigobon (2002) define contagion as a sudden increase in the correlation between stock market indices, whereas they refer to the mere correlation across markets as interdependence. Our spatial econometric approach does capture these cross-country correlations. We follow the 


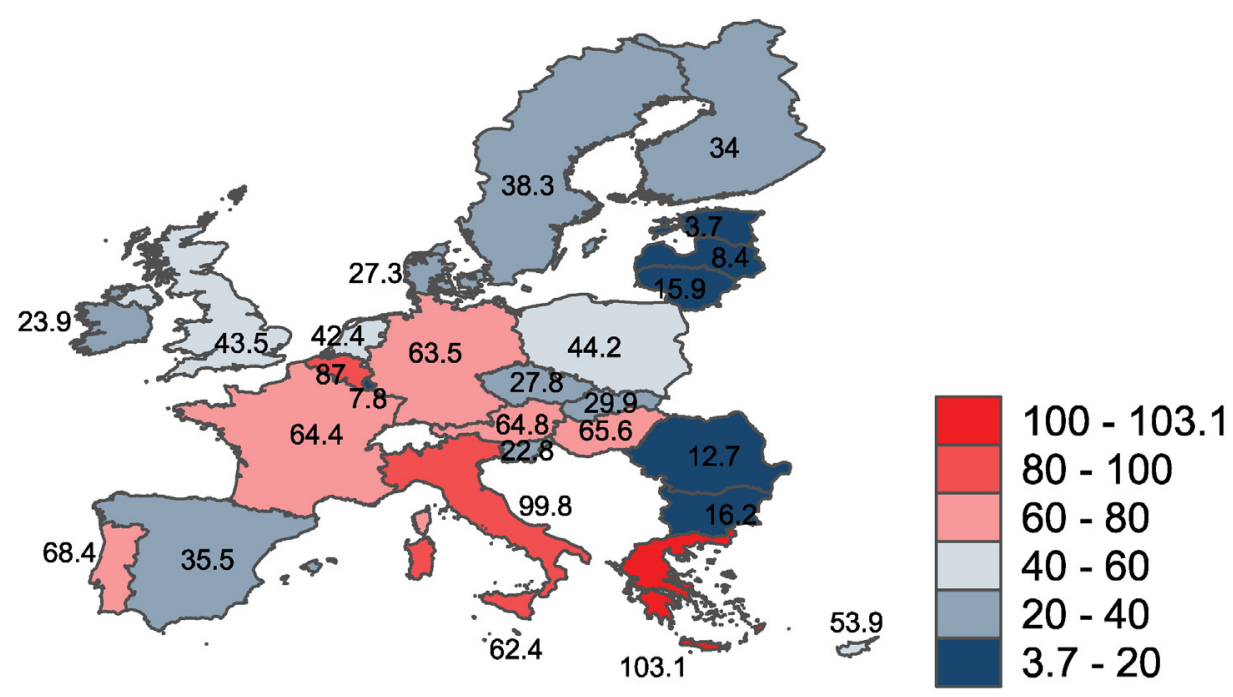

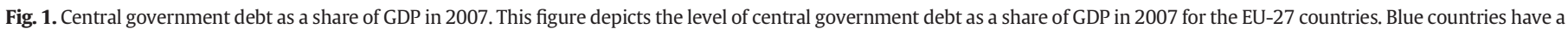

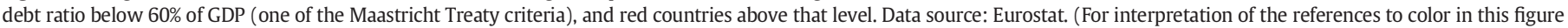
legend, the reader is referred to the web version of this article.)

definition by Forbes and Rigobon (2002) and refer to the cross-country correlation of FDI flows across host countries as interdependence.

The literature to date on interdependence across financial networks has not studied the potential for interdependence of FDI across FDI host countries with similar levels of public debt. Therefore, our paper can be seen as a first attempt to uncover another dimension of financial network structures, arising via FDI interdependence.

\section{Econometric modeling of FDI flows}

\subsection{Baseline gravity model}

In a first step, we follow the literature and estimate the following baseline model for FDI flows:

$$
\begin{aligned}
& \ln F D I_{i j}=\alpha_{0}+\alpha_{1} \ln Y_{i}+\alpha_{2} \ln Y_{j}+\alpha_{3} \ln P_{i}+\alpha_{4} \ln P_{j}+\alpha_{5} \ln D I S T_{i j}+ \\
& +\alpha_{6} \text { CONTIG }_{i j}+\alpha_{7} \text { COMLANG }_{i j}+\alpha_{8} \text { COLONY }_{i j}+\varepsilon_{i j}
\end{aligned}
$$

where ln denotes the natural logarithm and $F D I_{i j}$ denotes the value of bilateral FDI flows from country $i$ to $j . Y_{i}$ and $Y_{j}$ represent the economic size of the origin and destination countries, which we measure by their respective gross domestic product (GDP). Income is included in standard gravity models that analyze the determinants of FDI to proxy for the size of the economies: larger economies invest more and attract more investments (see, for example, Coughlin and Segev, 2000). $P_{i}$ and $P_{j}$ are the population of the origin and destination countries. Populations are included to control for the known tendency for FDI to move between wealthy markets and the associated parameter is expected to be negative (see Blonigen et al., 2007). ${ }^{8}$ CONTIG $_{i j}$ is a dummy that takes a value of 1 when countries share a border and 0 otherwise. COMLANG $G_{i j}$ is a dummy for countries sharing a language that is spoken by at least $9 \%$ of the population in both countries. COLONY $i j$ is a dummy that takes the value of 1 if both countries have a shared colonial past, and 0 otherwise. $D_{I S T}$ ij is calculated using bilateral distances between the largest cities of countries $i$ and $j$, with the intercity distances being weighted by the

\footnotetext{
8 This argument only applies to horizontal FDI. If firms invest in countries to exploit wage differences, one would expect the opposite sign, see Bénassy-Quéré et al. (2007) and Alamá-Sabater et al. (2016). Which of these two views prevails is an empirical question.
}

share of the city population in the country's overall population. Distance may have an ambiguous effect on FDI flows. As Portes and Rey (2005), Daude and Fratzscher (2008), and Márquez-Ramos (2011) among others all obtained a negative effect using a similar regression approach, we also expect a negative sign for $\alpha_{5}$. Finally, $\varepsilon_{i j}$ is the error term.

\subsection{Spatial gravity approach}

In the previous non-spatial regression specification, the flow of FDI from country $i$ to $j$ is completely determined by variables pertaining to countries $i$ and $j$ only. In other words, conventional regression models assume that outcomes for different units of observations are independent of each other. However, it is likely that investors exhibit some form of spatial correlation in terms of their FDI investment decisions across countries. This is especially true if there are unobserved common factors which affect the level of FDI flows and which may exhibit a spatial pattern. This is one of the key rationales for using spatial econometric models, see LeSage and Pace (2009). ${ }^{9}$ Generally, spatial correlation refers to the pair-wise correlation of observations of a random variable between two observations which are close in space. If the data are mapped out geographically, it might be assumed that outcomes at a given location depend on outcomes in nearby locations but not those further away.

This raises the question of how to measure the closeness of observations and how to quantify the importance of these spatial spillovers or interdependence of FDI flows. In addition, the question arises as to which dimension we use to define neighborhood: is neighborhood related to geographic space, i.e., the geographic distance between two different FDI host countries? Or are there other dimensions of space? In our regressions, we will construct a measure of neighborhood to determine whether there is interdependence of FDI flows between high public debt FDI host countries (and between low public debt host countries), while also controlling for the potential presence of more conventional geographic spillovers.

All our spatial weights should capture the fact that investors from one country will change their investment behavior not only in reaction

\footnotetext{
${ }^{9}$ For example, Haaland and Wooton (2007) stress the importance of labor market regulations such as employment protection measures for the FDI location decision. Measuring labor market institutions in quantitative regression models is notoriously difficult. As our measures of GDP are only a proxy for the investment conditions in the different markets, the presence of spatially correlated omitted factors seems a reasonable assumption.
} 


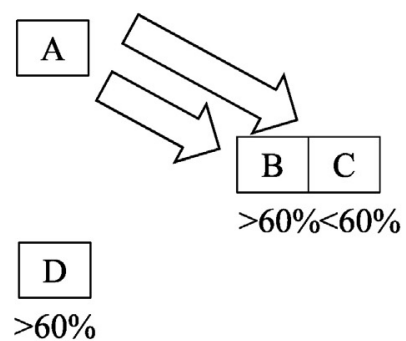

channel: geographic proximity

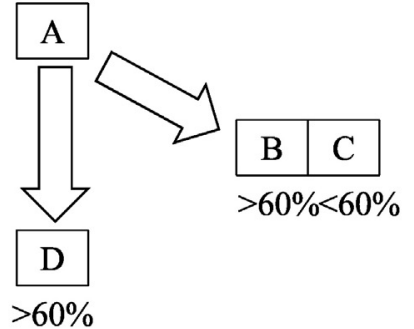

channel: Maastricht complier/non-complier

Fig. 2. Illustration of the different channels for interdependence between FDI host countries.

to changes in destination country $j$ but also in $j$ 's neighbors, i.e., we specify our spatial lag to capture the spillover effects in the destination of FDI flows. For ease of exposition, let us focus on the simplest neighborhood concept: sharing a common border. As explained by LeSage and Pace (2008), we can capture these destination spillovers in the following way: let $\overline{\mathbf{C}}^{C}$ denote a $n \times n$ contiguity matrix between the $n$ countries in our sample. Its typical entry $\bar{c}_{i j}$ is 1 if country $i$ and $j$ share a common border, and 0 otherwise; the main diagonal is set to 0 , as $i$ cannot be its own neighbor. $\mathbf{C}^{C}$ is the row-normalized counterpart to $\overline{\mathbf{C}}^{C}$ which we obtain by dividing each element in a particular row of $\overline{\mathbf{C}}^{C}$ by the sum of its entries in the respective row. Our data set has (potentially) $N=n^{2}$ observations, i.e., $N$ flows of FDI between country $i$ and $j$. Using an origin-centric ordering of our data set, ${ }^{10}$ we can then construct an amplified spatial weight matrix $\mathbf{W}^{C}$ with dimension $N \times N$ which defines a network among the FDI source country and the neighbors of the FDI host country, i.e., destination-based dependence as follows:

$\mathbf{W}^{C}=\mathbf{I}_{n} \otimes \mathbf{C}^{C}$,

where $\mathbf{I}_{n}$ is a $n \times n$ identity matrix and $\otimes$ denotes the Kronecker product.

Our regressor of interest, the spatial lag vector $\mathbf{W}^{C} \mathbf{y}$ (dimension $N \times 1$ ), contains $\sum_{j=1}^{N} w_{i j}^{C} \ln F D I_{i j}$, where $w_{i j}^{C}$ is the typical entry of $\mathbf{W}^{C}$ and $\mathbf{y}$ is the $N \times 1$ vector of the dependent variable. The spatial lag is obtained by averaging FDI flows across host countries which share a common border with the FDI host country. Its corresponding parameter $\rho_{1}$ measures the impact of spillover effects of FDI flows from the investing country to all countries with a common border of the FDI host country. Hence $\rho_{1}$ is a summary statistic of the impact of FDI flows into geographically close destination countries on the FDI flows into a particular destination country $j . \rho_{1}>0$ implies that higher inflows in geographically close countries lead to an increase in FDI in a particular host country, and lower inflows in geographically close countries lead to a decrease in FDI in a particular destination $j$.

Besides the role of geographic spillovers or interdependence, we want to test for the existence of an additional channel for FDI interdependence between FDI host countries which share similar levels of public debt. Therefore, we allow for interdependence of FDI destination flows if two destination countries have a level of public debt below 60\% of GDP, or if both of them have public debt above $60 \%$ of GDP, i.e., if both countries are violating the public debt criterion of the Maastricht Treaty. ${ }^{11}$ We denote the "debt contiguity" matrix by $\overline{\mathbf{C}}^{D}$, whose entries are either 0 (no debt contiguity) or 1 (debt contiguity). From Fig. 1, it can be seen that debt similarity makes countries such as Portugal and Greece direct neighbors, as they both have debt exceeding $60 \%$ of GDP, even though they do not share a common border, the conventional geographic indicator of neighborhood. Hence, our debt contiguity matrix captures a distinct

\footnotetext{
${ }^{10}$ For details, see LeSage and Pace (2008).

11 By this definition, we ensure that every country has at least one neighbor. This allows us to row-normalize the weight matrix by the sum of all entries.
}

dimension of neighborhood. The augmented spatial weight matrix which identifies neighboring FDI destination countries is denoted by $\mathbf{W}^{D}$ and is obtained by the equivalent of Eq. (2), i.e. $\mathbf{W}^{D}=\mathbf{I}_{n} \otimes \mathbf{C}^{D}$, where $\mathbf{C}^{D}$ is the row-normalized counterpart of $\overline{\mathbf{C}}^{D}$.

Adding both spatial lags to Eq. (1) leads to our main specification:

$$
\begin{aligned}
\ln F D I_{i j}= & \alpha_{0}+\alpha_{1} \ln Y_{i}+\alpha_{2} \ln Y_{j}+\alpha_{3} \ln P_{i}+\alpha_{4} \ln P_{j}+\alpha_{5} \ln D I S T_{i j}+ \\
& +\alpha_{6} C_{N O N I G_{i j}}+\alpha_{7} C_{O M L A N G}+\alpha_{8} C_{i j} O L O N Y_{i j} \\
& +\rho_{1} \sum_{j=1}^{N} w_{i j}^{C} \ln F D I_{i j}+\rho_{2} \sum_{j=1}^{N} w_{i j}^{D} \ln F D I_{i j}+\varepsilon_{i j} .
\end{aligned}
$$

Hence, further to the baseline bilateral gravity model of FDI as given in Eq. (1), we add not only a spatial lag of FDI flows into countries which share a common border with a destination country, as is standard in the literature using spatial gravity models of FDI, but, crucially, we also add the spatial lag of FDI flows into countries which have similar public debt levels (above/below the Maastricht criterion). This allows us to examine the new channel we propose for FDI interdependence.

Spatial lags introduce an endogeneity problem when estimating Eq. (3) by using OLS, see Anselin (1988) for the simplest case and LeSage and Pace (2009) for a more general treatment. We follow Anselin (1988) and use the instrumental variable (IV) estimator to get consistent parameter estimates. As instruments for the spatial lags for our data for 2007, we use the respective spatial lag of the time-lagged values of the dependent variable, i.e., $\sum_{j}^{N} w_{i j}^{C} \ln F D I_{i j, 2004}$ and $\sum_{j}^{N} w_{i j}^{D} \ln F D I_{i j, 2004}$. To perform overidentification tests, we construct another instrumental variable using a method inspired by MárquezRamos (2011). We run the following first-stage gravity regression of bilateral imports of country $i$ from country $j$ in 2004:

$$
\begin{aligned}
\ln M_{i j}= & \beta_{1} \ln D_{I S T} T_{i j}+\beta_{2} \ln C_{O N T I G}+\beta_{3} \text { COMLANG }_{i j}+ \\
& +\beta_{4} \text { COLONY }_{i j}+\mu_{i}+\nu_{j}+u_{i j},
\end{aligned}
$$

where DIST $_{i j}$, CONTIG $i j$, COMLANG $i j$, and COLONY $i j$ are defined as above. We also include importer and exporter dummies, $\mu_{i}$ and $\nu_{j}$, to control for the multilateral resistance terms which appear in trade gravity equations as suggested by Anderson and van Wincoop (2003). ${ }^{12}$ In a second step, the predicted logarithm of imports for year 2004 is calculated ( $\left.\widehat{\ln M}_{i j, 2004}\right)$ and, finally, this prediction is used as an additional excluded instrument for the endogenous spatial lags appearing in Eq. (3). ${ }^{13}$

\footnotetext{
12 Note that variables that vary only at the exporter or importer level such as income or population are perfectly collinear with exporter and importer fixed effects and are therefore controlled for by the fixed effects.

13 Note that to get a valid instrument, we do not necessarily need consistent estimates of the parameters of Eq. (4) as long as we receive an instrument which is correlated with our endogenous regressors but not correlated with the error term of Eq. (3). For a similar argument, see Felbermayr et al. (2010) and Heid and Larch (2012).
} 
Why is it that we can use the predicted value of imports of country $i$ from country $j$ in 2004 as an excluded instrument for the spatial lag of FDI in 2007? For a good instrument, we have to fulfill two conditions: relevance and exogeneity. As both imports and FDI flows are determined by exogenous geographic factors like distance between countries, both variables are correlated and are clearly relevant. Concerning exogeneity, our argument goes as follows: when investors decide on where to invest, they will focus on destination country characteristics such as the market potential in a destination country, especially in the case of horizontal FDI. Exports from $i$ to $j$ are also determined by the same factors, hence they would be endogenous. The imports of country $i$ from $j$, however, are determined by consumer demand in the importer $i$, and hence are independent of unobserved factors which determine FDI inflows into destination countries. ${ }^{14}$ An argument against this reasoning would be that vertical FDI predominates in FDI flows, as it depends on FDI source country characteristics in the sense that goods produced by foreign affiliates in the FDI destination countries are shipped back to the FDI origin country. However, vertical FDI crucially depends on wage differences due to, for example, differences in factor endowments. As we focus on FDI within the EU-27, where factor endowments are relatively similar, horizontal FDI is empirically more relevant, and our exclusion restriction is likely to hold. It is also in line with evidence presented by Kleinert and Toubal (2010) who find that models of horizontal FDI are more consistent with foreign affiliate sales data (and hence FDI). In the same vein, BajoRubio and Sosvilla-Rivero (1994) find that unit labor costs do not have a significant impact on the level of manufacturing FDI inflows in Spain.

\subsection{Data}

We use data on bilateral FDI flows in 2007 between the EU-27 members as well as the public debt-to-GDP ratio from Eurostat. Due to the log-linear specification, we only use positive FDI flows, which leaves us with 398 observations. FDI data comprise all investments by a direct investor in a destination country if the investment is equivalent to at least $10 \%$ of the voting power in the firm's decision-making body. FDI can take three different forms: investment in equity capital, reinvested earnings as well as other FDI capital such as loans. ${ }^{15}$ As an instrument for the endogenous spatial lag, we use the spatial lag using FDI data of 2004. For our first-stage regression for the construction of the additional instrument of predicted trade flows, we use data on bilateral imports of goods in 2004, also obtained from Eurostat.

Contiguity, common language, colonial relationship as well as distance are taken from the Centre d'études prospectives et d'informations internationales (CEPII). Income and population data are from the World Development Indicators (WDI).

\section{What drives FDI interdependence?}

\subsection{Dichotomous neighborhood criteria: geographic proximity versus Maastricht compliance}

We present estimates of Eq. (3) in Table 1. We use the dichotomous neighborhood criteria defined in the previous section, i.e., we consider the interdependence of FDI flows between FDI host countries who share a common border (geographic proximity) and between FDI host countries which are either both Maastricht compliers or both Maastricht non-compliers (Maastricht compliance). We present the OLS coefficient

\footnotetext{
14 For this to be strictly true, supply of goods has to be exogenous. While this is problematic in the long-run, capacity constraints, which are especially important in the short-run, can alleviate this problem.

${ }^{15}$ In the construction of the spatial lags, we replace missing values of FDI flows with zero. Hence, we effectively assume that countries with missing data do not have a spatial impact on other countries. Note, however, that we only do this in the construction of the spatia weights but do not replace missing values in the dependent variable. We believe that this is a good compromise between the need to set a specific spatial weight for every country pair and imputation of values we do not observe.
}

estimates of our baseline FDI regression, Eq. (1), in column (1). We find a positive and significant effect of the GDPs of the origin and host countries on FDI flows among the EU-27 members. We find that a 1\% increase in the GDP of the FDI country of origin increases FDI flows by $2.2 \%$. Interestingly, market size in the FDI host country also has a positive effect on FDI, but this effect is considerably lower: $0.6 \%$. Contiguity between countries and sharing a common language also increase bilateral FDI flows, whereas distance has a negative impact, in line with the argument that information frictions increase as distance increases, as argued by Portes and Rey (2005). As we control for GDP, it is not surprising that an increase in the population of both the origin and destination country lead to lower FDI flows, as an increase in population with a constant GDP translates into lower GDP per capita and hence a less attractive market. This may also be interpreted as evidence more in line with horizontal than vertical FDI motives if we interpret host country GDP per capita as a proxy for its wage level.

In Columns (2) to (6) we report the results of estimating the spatial gravity model for FDI given by Eq. (3) by IV. ${ }^{16}$ Column (2) includes the spatial lag where we allow for interdependence of FDI flows across host countries if both FDI host countries share a common border. Qualitatively, the spatial model validates the results obtained using the baseline model (i.e., column 1). However, coefficients are mostly smaller in absolute magnitudes than in the non-spatial model. Distance in particular has a lower impact on FDI flows when the spatial lag is included. The impact of country-of-origin GDP is reduced to $1.4 \%$. This illustrates the potential bias of non-spatial models, especially given the fact that we find a positive and significant effect of the spatial lag: the higher the investments received by an EU country, the higher the investments received by adjacent FDI destination countries. Similarly, a sudden fall in FDI in one country is correlated with a reduction in FDI in contiguous countries. This highlights the interdependence of FDI flows within Europe and confirms previous findings in the literature, e.g., Blonigen et al. (2007), Leibrecht and Riedl (2014) and Alamá-Sabater et al. (2016). It is also an indication of the public good nature of FDI in the European Union: policies which attract FDI to a particular EU member country lead to a positive spillover in adjacent countries. This potentially creates a free-rider problem if countries can benefit from a policy change in their neighbors that improves their investment climate, attracting more FDI. It also implies that a sudden fall in the attractiveness of an FDI host country will not only reduce FDI in that particular country but also in its neighbors.

In column (3) we drop the spatial lag based on a common border between FDI host countries. Instead, we now allow for interdependence of FDI flows between host countries which are either both above or both below the Maastricht debt criterion of $60 \%$ of GDP.

We also find a positive and significant effect for the public debt channel. The estimated coefficient is even larger than the coefficient for interdependence across FDI host countries with a common border, which we interpret as evidence of larger interdependence of FDI inflows due to the public debt channel than due to the geographic proximity channel. Hence, FDI flows into a particular country are correlated with FDI flows into countries who are on the same page in terms of whether or not they comply with the Maastricht criterion. The remaining coefficients are similar in magnitude; however, contiguity loses its significance.

To rule out the possibility that our debt contiguity measure picks up the interdependence of FDI flows between host countries which share a common border, we simultaneously include both spatial lags in column (4). Our control variables remain similar in magnitude but contiguity

\footnotetext{
16 Table A.1 in the Appendix shows the results from the first stage that creates the additional instrument: contiguity and colonial links have a positive impact on trade, whereas distance has a negative impact on imports, as expected according to the literature on trade flows. Common language is not significant. Note that as we include predicted imports in 2004 as an instrument in addition to the spatial lags in 2004, we can perform Hansen's overidentification test (OIT). We report the $p$-values of the corresponding $J$ statistics at the bottom of Tables 1 and 2 . All our specifications pass the OIT; the endogeneity test rejects the exogeneity of the spatial lags, vindicating our use of IV. Hence, our models pass standard specification tests.
} 
Table 1

Spatial gravity of FDI flows in 2007: dichotomous neighborhood criteria.

\begin{tabular}{|c|c|c|c|c|c|c|}
\hline & (1) & $(2)$ & $(3)$ & (4) & (5) & (6) \\
\hline & $\ln F D I_{i j}$ & $\ln F D I_{i j}$ & $\ln F D I_{i j}$ & $\ln F D I_{i j}$ & $\ln F D I_{i j}$ & $\ln F D I_{i j}$ \\
\hline CONSTANT & $\begin{array}{l}6.444^{\text {**** }} \\
(2.069)\end{array}$ & $\begin{array}{l}4.278^{* *} \\
(2.156)\end{array}$ & $\begin{array}{l}4.740 * * \\
(2.016)\end{array}$ & $\begin{array}{l}3.850^{*} \\
(2.030)\end{array}$ & $\begin{array}{l}3.682^{*} \\
(2.018)\end{array}$ & $\begin{array}{l}3.690^{*} \\
(1.992)\end{array}$ \\
\hline $\ln Y_{i}$ & $\begin{array}{l}2.175^{* * * *} \\
(0.128)\end{array}$ & $\begin{array}{l}1.416^{* * * *} \\
(0.199)\end{array}$ & $\begin{array}{l}1.085^{* * * *} \\
(0.217)\end{array}$ & $\begin{array}{l}0.925^{* * * *} \\
(0.234)\end{array}$ & $\begin{array}{l}1.097^{\text {*** }} \\
(0.213)\end{array}$ & $\begin{array}{l}0.905^{* * * *} \\
(0.225)\end{array}$ \\
\hline $\ln Y_{j}$ & $\begin{array}{l}0.627^{* * *} \\
(0.138)\end{array}$ & $\begin{array}{l}0.516^{* * *} \\
(0.138)\end{array}$ & $\begin{array}{l}0.702^{* * *} \\
(0.139)\end{array}$ & $\begin{array}{l}0.606^{* * *} \\
(0.136)\end{array}$ & $\begin{array}{l}0.558^{* * * *} \\
(0.129)\end{array}$ & $\begin{array}{l}0.613^{* * *} \\
(0.133)\end{array}$ \\
\hline $\ln P_{i}$ & $\begin{array}{l}-1.549^{* * *} \\
(0.141)\end{array}$ & $\begin{array}{l}-1.050^{* * * *} \\
(0.177)\end{array}$ & $\begin{array}{l}-0.781^{\text {**** }} \\
(0.184)\end{array}$ & $\begin{array}{l}-0.692^{* * *} \\
(0.194)\end{array}$ & $\begin{array}{l}-0.822^{* * *} \\
(0.172)\end{array}$ & $\begin{array}{l}-0.677^{* * *} \\
(0.184)\end{array}$ \\
\hline $\ln P_{j}$ & $\begin{array}{l}-0.341^{* *} \\
(0.162)\end{array}$ & $\begin{array}{l}-0.362^{* *} \\
(0.162)\end{array}$ & $\begin{array}{l}-0.372^{* *} \\
(0.163)\end{array}$ & $\begin{array}{l}-0.377^{* *} \\
(0.159)\end{array}$ & $\begin{array}{l}-0.266^{*} \\
(0.152)\end{array}$ & $\begin{array}{l}-0.302^{*} \\
(0.156)\end{array}$ \\
\hline $\ln D I S T_{i j}$ & $\begin{array}{l}-0.867^{* * * *} \\
(0.170)\end{array}$ & $\begin{array}{l}-0.346^{*} \\
(0.194)\end{array}$ & $\begin{array}{l}-0.793^{\text {**** }} \\
(0.159)\end{array}$ & $\begin{array}{l}-0.475^{* *} \\
(0.185)\end{array}$ & $\begin{array}{l}-0.563^{\text {**** }} \\
(0.162)\end{array}$ & $\begin{array}{l}-0.617^{* * *} \\
(0.160)\end{array}$ \\
\hline CONTIG $_{i j}$ & $\begin{array}{l}0.635^{* *} \\
(0.314)\end{array}$ & $\begin{array}{l}1.401^{* * *} \\
(0.356)\end{array}$ & $\begin{array}{l}0.467 \\
(0.302)\end{array}$ & $\begin{array}{l}1.020^{* * *} \\
(0.354)\end{array}$ & $\begin{array}{l}0.728^{* *} \\
(0.316)\end{array}$ & $\begin{array}{l}0.624^{* *} \\
(0.308)\end{array}$ \\
\hline$C_{C O M L A N G}$ & $\begin{array}{l}1.035^{* * *} \\
(0.295)\end{array}$ & $\begin{array}{l}1.049^{* * * *} \\
(0.376)\end{array}$ & $\begin{array}{l}1.445^{* * *} \\
(0.351)\end{array}$ & $\begin{array}{l}1.328^{* * * *} \\
(0.374)\end{array}$ & $\begin{array}{l}0.941^{* * * *} \\
(0.349)\end{array}$ & $\begin{array}{l}1.157^{* * * *} \\
(0.365)\end{array}$ \\
\hline $\mathrm{COLONY}_{i j}$ & $\begin{array}{l}0.433 \\
(0.429)\end{array}$ & $\begin{array}{l}0.922 \\
(0.561)\end{array}$ & $\begin{array}{l}0.713 \\
(0.450)\end{array}$ & $\begin{array}{l}0.946^{*} \\
(0.516)\end{array}$ & $\begin{array}{l}0.843 \\
(0.531)\end{array}$ & $\begin{array}{l}0.854^{*} \\
(0.509)\end{array}$ \\
\hline $\begin{array}{l}\text { Channels of FDI interdependence: spa } \\
\text {...common border }\end{array}$ & ed on neight & $\begin{array}{l}\text { efined by... } \\
0.468^{* * * *} \\
(0.089)\end{array}$ & & $\begin{array}{l}0.306^{* * *} \\
(0.097)\end{array}$ & & \\
\hline ...Maastricht complier/non-complier & & & $\begin{array}{l}0.625^{* * *} \\
(0.097)\end{array}$ & $\begin{array}{l}0.432^{* * *} \\
(0.120)\end{array}$ & & $\begin{array}{l}0.288^{* *} \\
(0.135)\end{array}$ \\
\hline ...within $1000 \mathrm{~km}$ & & & & & $\begin{array}{l}0.590^{* * *} \\
(0.096)\end{array}$ & $\begin{array}{l}0.421^{* * *} \\
(0.125)\end{array}$ \\
\hline $\mathrm{N}$ & 398 & 398 & 398 & 398 & 398 & 398 \\
\hline$R^{2}$ & 0.525 & 0.471 & 0.530 & 0.513 & 0.525 & 0.538 \\
\hline $\ln \mathcal{L}$ & -809.3 & -830.9 & -807.3 & -814.4 & -809.3 & -803.9 \\
\hline OIT J statistic ( $p$-value) & & 0.353 & 0.802 & 0.772 & 0.829 & 0.997 \\
\hline Endog. test $\chi^{2}$ ( $p$-value) & & $1.43 e-05$ & $8.50 \mathrm{e}-06$ & $4.43 e-06$ & $8.09 e-05$ & $2.54 \mathrm{e}-05$ \\
\hline
\end{tabular}

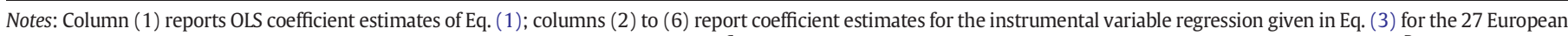

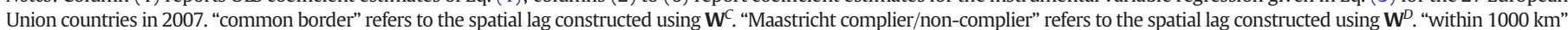

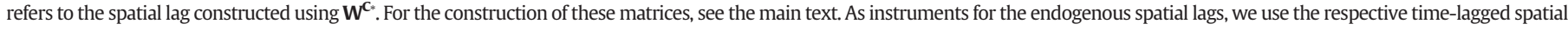
lags using $\ln F D I_{i j}$ from 2004 as well as predicted log imports, $\widehat{\ln }_{i j}$, in 2004 from the first-stage regression presented in Table A.1 in the Appendix. Robust standard errors in parentheses.

*** $p<0.01$.

** $p<0.05$

* $p<0.1$.

regains its significance. Most importantly, we find a positive and significant impact of both spatial lags. Hence, FDI flows into a particular country are correlated with FDI flows into contiguous countries as well as into countries with the same status as a Maastricht (non-)complier. The debt channel for FDI interdependence also remains the more important channel, even after controlling for the geography channel. Therefore, a sudden change in FDI inflows into a country leads to similar changes in destination countries with a similar Maastricht status. This highlights a novel channel for potential spillovers of fiscal policy across countries: lower investments in a country which does not comply with the $60 \%$ threshold of public debt in terms of GDP are correlated with lower investments in other countries that are also non-compliant in terms of the debt criterion. In that sense, our aggregate FDI regressions are consistent with the notion that investors perceive two distinct groups of countries: Maastricht compliers and non-compliers.

Until now, we have defined geographic proximity as sharing a common border. Hence Malta and Cyprus do not have any neighbors. ${ }^{17}$ It is conceivable that there is interdependence between FDI flows into Cyprus and Greece, or between those into Malta and Italy, simply due to their geographic closeness. If this is true, this correlation is picked up by the spatial lag using the public debt criterion, at least for Malta and Italy, as both are above the Maastricht criterion. To check that our results are not driven by this possibility, we construct another spatial lag to measure the interdependence between geographically close

\footnotetext{
17 We have set the row-standardized weights for these countries to 0 .
}

host countries by defining neighbors as all host countries with capital cities within a range of $1000 \mathrm{~km} .{ }^{18}$ We present the estimates for this spatial lag in column (5). When comparing with column (2), we find broadly similar results, irrespective of the specific measure of geographic proximity chosen. In column (6), we include both measures, the new geographic proximity spatial lag as well as the Maastricht criterion spatial lag. The estimates for our control variables are similar to column (4). However, we now find that geographic interdependence between FDI host countries is larger than the interdependence via the public debt channel. We still find that FDI flows are correlated between host countries with a similar Maastricht status, even when controlling for geographic interdependence. Our results show that the two channels reflect distinct dimensions of FDI interdependence, corroborating our reading of Fig. 1.

This is also consistent with the findings of Claeys et al. (2012). They find that similarity in the level of bond market capitalization (measured as the share of GDP) leads to interdependence between interest rates across EU countries. As their bond market measure also includes public debt, their channel for potential interactions is similar to our measure of public debt similarity. Foreign investors take into account the level of interest rates, so an interdependence of interest rates in line with the similarity of public debt naturally translates to a corresponding

\footnotetext{
18 Hence we create a $n \times n$ matrix $\overline{\mathbf{C}}^{C^{*}}$ whose typical entry is 1 if the capitals of countries $i$ and $j$ are within $1000 \mathrm{~km}$, and 0 otherwise, and where we set the main diagonal to 0 . We can then create $\mathbf{C}^{\mathrm{C} *}$, its row-normalized counterpart. The spatial lag is then constructed using $\mathbf{W}^{C *}=\mathbf{I}_{n} \otimes \mathbf{C}^{C *}$.
} 
Table 2

Spatial gravity of FDI flows in 2007: continuous neighborhood criteria.

\begin{tabular}{|c|c|c|c|c|c|c|}
\hline & (1) & (2) & (3) & (4) & (5) & (6) \\
\hline & $\ln F D I_{i j}$ & $\ln F D I_{i j}$ & $\ln F D I_{i j}$ & $\ln F D I_{i j}$ & $\ln F D I_{i j}$ & $\ln F D I_{i j}$ \\
\hline CONSTANT & $6.444^{* * *}$ & $4.661^{* *}$ & $4.738^{* *}$ & $4.641^{* *}$ & $4.757^{* *}$ & $3.685^{*}$ \\
\hline & $(2.069)$ & $(1.977)$ & $(2.005)$ & (1.995) & $(1.984)$ & $(1.984)$ \\
\hline $\ln Y_{i}$ & $2.175^{* * * *}$ & $0.914^{* * * *}$ & $0.987^{* * * *}$ & $0.923^{* * * *}$ & $0.958^{* * * *}$ & $0.896^{* * * *}$ \\
\hline & $(0.128)$ & $(0.224)$ & $(0.231)$ & $(0.231)$ & $(0.228)$ & $(0.231)$ \\
\hline $\ln Y_{j}$ & $0.627^{* * * *}$ & $0.674^{* * * *}$ & $0.691^{* * * *}$ & $0.675^{* * * *}$ & $0.647^{* * * *}$ & $0.600^{* * * *}$ \\
\hline & $(0.138)$ & $(0.135)$ & $(0.138)$ & $(0.137)$ & $(0.134)$ & $(0.133)$ \\
\hline $\ln P_{i}$ & $-1.549^{* * *}$ & $-0.668^{* * *}$ & $-0.688^{* * *}$ & $-0.651^{* * *}$ & $-0.737^{* * *}$ & $-0.663^{* * *}$ \\
\hline & $(0.141)$ & $(0.184)$ & $(0.194)$ & $(0.193)$ & $(0.196)$ & $(0.191)$ \\
\hline $\ln P_{j}$ & $-0.341^{* *}$ & $-0.345^{* *}$ & $-0.372^{* *}$ & $-0.362^{* *}$ & $-0.311^{* *}$ & $-0.296^{*}$ \\
\hline & $(0.162)$ & $(0.158)$ & $(0.163)$ & $(0.162)$ & $(0.157)$ & $(0.156)$ \\
\hline $\ln D I S T_{i j}$ & $-0.867^{* * *}$ & $-0.796^{\text {**** }}$ & $-0.833^{* * *}$ & $-0.806^{* * *}$ & $-0.757^{* * *}$ & $-0.623^{* * *}$ \\
\hline & $(0.170)$ & $(0.154)$ & $(0.156)$ & $(0.155)$ & $(0.154)$ & $(0.160)$ \\
\hline $\mathrm{CONTIG}_{i j}$ & $0.635^{* *}$ & $0.527^{*}$ & $0.486^{*}$ & $0.491^{*}$ & $0.590^{* *}$ & $0.648^{* *}$ \\
\hline & $(0.314)$ & $(0.294)$ & $(0.294)$ & $(0.294)$ & $(0.301)$ & $(0.306)$ \\
\hline COMLANG $_{i j}$ & $1.035^{* * * *}$ & $1.274^{* * * *}$ & $1.337^{* * * *}$ & $1.346^{* * * *}$ & $1.171^{* * * *}$ & $1.080^{* * * *}$ \\
\hline & $(0.295)$ & $(0.353)$ & $(0.357)$ & $(0.356)$ & $(0.355)$ & $(0.365)$ \\
\hline $\mathrm{COLONY}_{i j}$ & 0.433 & 0.686 & 0.678 & 0.710 & 0.670 & $0.839^{*}$ \\
\hline & $(0.429)$ & $(0.436)$ & $(0.437)$ & $(0.441)$ & $(0.439)$ & $(0.506)$ \\
\hline Channels of FDI interdepen & al lag based & hood defined & & & & \\
\hline ...inverse distance & & $0.715^{* * *}$ & & & $1.537^{* *}$ & \\
\hline & & $(0.106)$ & & & $(0.604)$ & \\
\hline ...debt similarity & & & $0.673^{* * *}$ & & -0.845 & 0.261 \\
\hline & & & $(0.109)$ & & $(0.618)$ & $(0.165)$ \\
\hline ...inv. distance $\&$ debt sim. & & & & $0.706^{* * *}$ & & \\
\hline & & & & $(0.109)$ & & \\
\hline ...within $1000 \mathrm{~km}$ & & & & & & $0.448^{* * *}$ \\
\hline & & & & & & $(0.137)$ \\
\hline $\mathrm{N}$ & 398 & 398 & 398 & 398 & 398 & 398 \\
\hline$R^{2}$ & 0.525 & 0.554 & 0.541 & 0.547 & 0.561 & 0.540 \\
\hline $\ln \mathcal{L}$ & -809.3 & -796.7 & -802.6 & -799.9 & -793.6 & -803.0 \\
\hline OIT J statistic ( $p$-value) & & 0.974 & 0.991 & 0.958 & 0.812 & 0.955 \\
\hline Endog. test $\chi^{2}$ ( $p$-value) & & 0.000596 & 0.000130 & 0.000304 & 0.00486 & 0.000116 \\
\hline
\end{tabular}

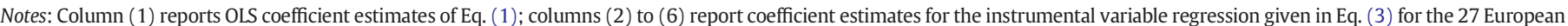

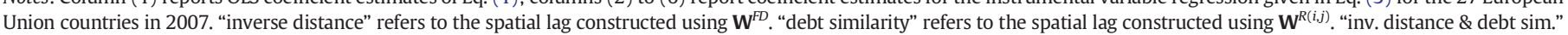

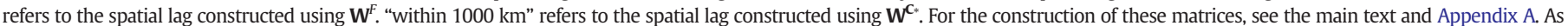

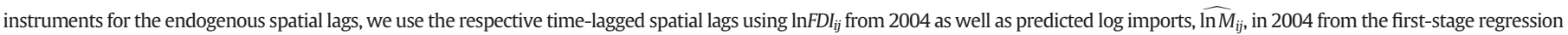
presented in Table A.1 in the Appendix. Robust standard errors in parentheses.

*** $p<0.01$.

** $p<0.05$.

* $p<0.1$.

interdependence of FDI flows. In that sense, our results can be interpreted as a kind of mirror image of Claeys et al. (2012).

\subsection{Continuous neighborhood criteria: inverse distance versus public debt similarity}

Until now, we have used an "all or nothing" criterion for debt contiguity to model FDI interdependence. However, it is an empirical question whether interdependencies really only occur if both host countries have violated the Maastricht criterion or not, or whether the interdependence occurs more generally between host countries with similar levels of public debt. For example, consider the case of Germany versus the United Kingdom: in 2007, the UK had a level of public debt of $43.5 \%$ of GDP, whereas Germany had $63.5 \%$. According to our debt contiguity measure from the previous section, these two host countries would not be considered neighbors. However, it seems possible that FDI interdependence will more likely occur between Germany and the UK than between Germany and, say, Greece, a country which also violates the Maastricht criterion but whose level of public debt is $103.1 \%$ of GDP. In other words, it seems plausible to use a measure of similarity of public debt that allows for a continuous metric of neighborhood. Similarly, FDI flows into countries may be more correlated, the closer they are. Instead of defining neighborhood in a dichotomous way as we did in the previous section, one could also use a continuous weight which decreases with increasing distance.
Therefore, we introduce a new method for modeling continuous neighborhood measures, so-called "fuzzy metrics", to specify spatial weight matrices. This allows us to model FDI interdependence in a continuous fashion. In addition, fuzzy metrics allow us to combine several neighborhood dimensions into one spatial weight matrix. Thus we can investigate, for example, the combined effect of geographic proximity and public debt similarity using one summary measure to construct the weights in our spatial weight matrix.

Fuzzy metric spaces have been investigated from different points of view. We use the concept of a fuzzy metric space by George and Veeramani (1994). To the best of our knowledge, fuzzy metrics have not been used to create spatial weight matrices for spatial econometric models before. However, there are antecedents in the literature which are similar to our approach. For example, Bodson and Peeters (1975), as cited in Anselin (1988), measure the accessibility of a particular region by several modes of transportation using a weighted average of (scaled) inverse distances for the different travel modes, an approach which is somewhat similar in spirit to ours.

We will use two fuzzy metrics: a continuous measure of geographic proximity related to the inverse distance between FDI host countries $i$ and $j, M_{d}(i, j)$, and a continuous measure of the similarity of the level of public debt between FDI host countries $i$ and $j, R(i, j)$. We use these measures to construct row-normalized spatial weight matrices, in the same way as we used the dichotomous contiguity matrix and the Maastricht complier/non-complier matrix in Section 3.2. Interested 
readers may consult Appendix A for the mathematical details, but here it suffices to say that the spatial weights using $M_{d}(i, j)$ decrease with increasing distance between FDI host countries, and also decrease with an increasing difference between the public debt-to-GDP ratios of FDI host countries when using $R(i, j)$. The latter allows us to see whether the interdependence between FDI flows into host countries is really related to the fact that both host countries have the same status as either Maastricht complier or non-complier, as we have seen in Section 4.1, or whether the interdependence is higher when the respective levels of public debt of the FDI host countries are more similar.

We present results using these weight matrices in Table 2. For convenience, column (1) reproduces the baseline regression results from Table 1. Column (2) uses the fuzzy measure of inverse distance to gauge the interdependence between geographically close FDI host countries. Results are very similar to column (2) from Table 1. Again, we find that the impact of origin country GDP decreases, and in this case even further, to about half of the estimate from the non-spatial model. We find evidence of interdependence between FDI flows into geographically close host countries also when using the fuzzy inverse distance measure. Column (3) swaps the spatial lag using geographic proximity with the spatial lag measuring similarity in the public debt level. Again, similar to Table 1, we find that FDI flows are correlated between host countries with similar public debt levels.

In column (4), we use a spatial weight matrix which uses the product of $M_{d}(i, j)$ and $R(i, j), C_{i j}$, to construct the spatial weights. This summary measure allows for the interdependence of FDI flows between host countries which are either geographically close or share a similar level of public debt. Results for our control variables are very similar to columns (2) and (3). Our estimate of the interdependence between FDI host countries lies between the estimate of columns (2) and (3), consistent with the fact that we use the product of both dimensions to create the single weight matrix.

Column (5) simultaneously includes both spatial lags from columns (2) and (3). Interestingly, we now find that FDI flows into host countries are significant and positively correlated only between geographically close FDI host countries. Similar debt-to-GDP ratios in FDI host countries, however, do not lead to FDI interdependence between destinations. ${ }^{19}$ It seems as if the Maastricht criterion really does provide a signal to investors which informs their investment decisions, irrespective of whether countries only just miss the mark or far exceed the debt criterion.

To check whether the continuous measure for geographic proximity is responsible for the loss of significance of the debt similarity measure, in column (6) we include the spatial lag which uses the dichotomous geographic proximity variable (distance between capitals of FDI host countries is $<1000 \mathrm{~km}$ ) instead of the fuzzy inverse distance measure. Again, we do not find evidence for interdependence of FDI flows into host countries with similar levels of public debt when controlling for the channel of interdependence due to geographic proximity.

In sum, we find that FDI flows into host countries are interdependent among the EU-27 countries. We find evidence for both interdependence due to geographic proximity as well as due to similarity of public debt levels between FDI destination countries. However, it seems that the latter type of spillover only operates between host country pairs above or below the Maastricht criterion; if we focus only on similarity in debt-to-GDP ratios, we do not find evidence for FDI interdependence when also controlling for potential geographic FDI spillovers in host countries.

It seems that the Maastricht criterion does inform investors' FDI location decisions and they categorize countries as either "Maastricht compliers" or "non-compliers", whereas the underlying actual level of

\footnotetext{
19 Again, specification tests do not reject the validity of our estimated models. Instruments pass the overidentification test for exogeneity and the endogeneity test reports that the spatial lags are endogenous. Also note that the stationarity restriction for a model with two weighting matrices is that the sum of the spatial lag coefficients lies in $[-1 ; 1]$, see LeSage and Pace (2009), p. 221. Our estimates in both Tables 1 and 2 fulfill this condition.
}

public debt to GDP is ignored. This may be interpreted as evidence for the importance of more or less arbitrary thresholds and policy goals as they may give investors an easily observed signal of macro-prudential policies. This highlights the importance of institutional determinants such as the (perceived) sustainability of public finances for the stability of FDI flows, in addition to general economic, geographic and cultural factors like GDP, distance and common language. This also corroborates findings by Portes and Rey (2005) who stress informational frictions as important determinants of FDI flows.

\section{Conclusions}

This paper analyzes the potential correlation or interdependence of FDI flows between the EU-27 countries in 2007. Specifically, we consider FDI interdependence across geographically close FDI host countries and those host countries with similar public debt characteristics, namely similar levels of public debt or whether two host countries have a public debt-to-GDP ratio exceeding $60 \%$ and thus violate the Maastricht criterion, or not. Using a spatial gravity equation of bilateral FDI flows, we find that both these channels matter for FDI interdependence, in addition to traditional determinants of FDI like market size and distance.

Interestingly, the Maastricht Treaty threshold of a maximum of $60 \%$ of public debt over GDP is important for the interdependence of FDI flows: if both FDI host countries violate the Maastricht criterion, the correlation between FDI flows is significantly higher. It is also higher if both countries do not violate the criterion. On the contrary, when modeling interdependence as occurring between host countries with similar levels of public debt (i.e., without explicitly considering the threshold level of public debt established in the Maastricht Treaty), we do not find evidence of FDI interdependence once the channel of geographic proximity is taken into account. It would appear that a violation of the Maastricht debt criterion is an important determinant of FDI interdependence as it provides a simple and easily observable signal to investors. Investors perceive countries that violate the Maastricht criterion to share some common characteristics. They may view FDI in these countries as riskier investments due to nonsustainable public debt levels which might have a negative impact on the expected return on the investment, especially when aggregate demand conditions in the destination market are key to the investment decision. There also seem to be similarities between countries that do not violate the Maastricht criterion in terms of their potential for attracting FDI. This implies that a potential withdrawal of FDI from, for example, a country which violates the Maastricht criterion will likely also lead to withdrawals of FDI from other Maastricht-violating countries, whereas countries that do not violate the criterion will not be affected by this channel of interdependence. Therefore, our research has important policy implications for governments which try to attract FDI.

\section{Appendix A. Using fuzzy metrics to construct spatial weight matrices}

Following George and Veeramani (1994), Sapena (2001), and Gregori et al. (2005), we define the fuzzy metric $M_{d}$ as follows:

$$
M_{d}(i, j)=\frac{M}{M+D I S T(i, j)}
$$

where $i$ and $j$ denote two countries, $\operatorname{DIST}(i, j)$ is the distance between the countries and $M=\max \{\operatorname{DIST}(i, j): i, j\}$. We can then use $M_{d}(i, j)$ as the entry in a non-row-normalized spatial weight matrix. Clearly, the weight for two distant countries is smaller than the weight between two close countries. Note that this is very similar to creating weights by using the inverse distance as is often done by spatial econometricians. We set the main diagonal of the resulting weight matrix equal to 0 and row-normalize the matrix, as is standard in spatial econometric applications. We denote the resulting spatial weight matrix by $\mathbf{C}^{F D}, F D$ for "fuzzy distance". We can then use this matrix to create the according 
spatial lag vector $\mathbf{W}^{F D} \mathbf{y}$, where $\mathbf{W}^{F D}=\mathbf{I}_{n} \otimes \mathbf{C}^{F D}$, the equivalent to Eq. (2) in the main text, and $\mathbf{y}$ denotes the dependent variable.

As our measure of the similarity of public debt levels, we use the following fuzzy metric ${ }^{20}$ :

$R(i, j)=\frac{\min \{\operatorname{DEBTSHARE}(i), \operatorname{DEBTSHARE}(j)\}+1}{\max \{\operatorname{DEBTSHARE}(i), \operatorname{DEBTSHARE}(j)\}+1}$,

where DEBSTSHARE denotes the level of public debt in terms of a percentage of GDP. $R(i, j)$ lies between 0 and 1 and is maximized if both countries have the same level of public debt. For diverging levels of debt between the two countries, $R(i, j)$ approaches 0 . We can then use $R(i, j)$ as the entry in a non-row-normalized spatial weight matrix. As before, we set the main diagonal of the resulting weight matrix equal to 0 and row-normalize the matrix. We denote the resulting spatial weight matrix by $\mathbf{C}^{R(i, j)}$ and its augmented destination counterpart by $\mathbf{W}^{R(i, j)}=\mathbf{I}_{n} \otimes \mathbf{C}^{R(i, j)}$. We use it to construct the pertaining spatial lag for our regressions, $\mathbf{W}^{R(i, j)} \mathbf{y}$.

Finally, we can create another fuzzy metric which combines both fuzzy metrics introduced above:

$C_{i j}=M_{d}(i, j) * R(i, j)$,

where $C_{i j}$ is the product of the two individual fuzzy metrics $M_{d}(i, j)$ and $R(i, j)$. As before, we set the main diagonal of the resulting weight matrix equal to 0 and row-normalize the matrix. We denote the resulting spatial weight matrix by $\mathbf{C}^{F}$ and its augmented destination counterpart by $\mathbf{W}^{F}=\mathbf{I}_{n} \otimes \mathbf{C}^{F}$. Its weights increase if either the distance between countries $i$ and $j$ is small or if they have similar levels of public debt, and decrease if the countries are far apart or have different levels of public debt. We use it to construct the pertaining spatial lag $\mathbf{W}^{F} \mathbf{y}$.

Obviously, this metric can be generalized to include more dimensions.

\section{Appendix B. First-stage regression}

Table A.1

First-stage regression for external instrument

\begin{tabular}{|c|c|}
\hline & \multirow{2}{*}{$\frac{(1)}{\ln M_{i j}}$} \\
\hline & \\
\hline $\ln D I S T_{i j}$ & $\begin{array}{l}-1.248^{* * *} \\
(0.078)\end{array}$ \\
\hline CONTIG $_{i j}$ & $\begin{array}{l}0.303^{* *} \\
(0.149)\end{array}$ \\
\hline COMLANG $_{i j}$ & $\begin{array}{l}0.163 \\
(0.208)\end{array}$ \\
\hline $\mathrm{COLONY}_{i j}$ & $\begin{array}{l}0.547^{\text {*** }} \\
(0.207)\end{array}$ \\
\hline Importer FEs & YES \\
\hline Exporter FEs & YES \\
\hline $\mathrm{N}$ & 702 \\
\hline$R^{2}$ & 0.915 \\
\hline $\ln \mathcal{L}$ & -816.3 \\
\hline
\end{tabular}

Notes: Results for the first-stage import gravity regression given in Eq. (4) for the 27 European Union countries in 2004. Robust standard errors in parentheses.

*** $p<0.01$.

** $p<0.05$.

\section{References}

Acemoglu, D., Ozdaglar, A., Tahbaz-Salehi, A., 2015. Systemic risk and stability in networks. Am. Econ. Rev. 105 (2), 564-608.

Alamá-Sabater, L., Heid, B., Jiménez-Fernández, E., Márquez-Ramos, L., 2016. FDI in space revisited: the role of spillovers on foreign direct investment within the European Union. Growth and Change (forthcoming).

Allen, F., Gale, D., 2000. Financial contagion. J. Polit. Econ. 108 (1), 1-33.
Anderson, J.E., van Wincoop, E., 2003. Gravity with gravitas: a solution to the border puzzle. Am. Econ. Rev. 93 (1), 170-192

Anselin, L., 1988. Spatial Econometrics: Methods and Models. Kluwer Academic Publishers, Dordrecht

Babus, A., 2016. The formation of financial networks. RAND J. Econ. 47 (2), 239-272.

Bajo-Rubio, O., Sosvilla-Rivero, S., 1994. An econometric analysis of foreign direct investment in Spain. South. Econ. J. 61 (1), 104-120.

Baltagi, B.H., Egger, P., Pfaffermayr, M., 2007. Estimating models of complex FDI: are there third-country effects? J. Econ. 140 (1), 260-281.

Baltagi, B.H., Egger, P., Pfaffermayr, M., 2008. Estimating regional trade agreement effects on FDI in an interdependent world. J. Econ. 145 (1-2), 194-208.

Bénassy-Quéré, A., Coupet, M., Mayer, T., 2007. Institutional determinants of foreign direct investment. World Econ. 30 (5), 764-782.

Bergstrand, J.H., Egger, P., 2007. A knowledge-and-physical-capital model of international trade flows, foreign direct investment, and multinational enterprises. J. Int. Econ. 73 (2), 278-308.

Blanco, L.R., 2012. The spatial interdependence of FDI in Latin America. World Dev. 40 (7), 1337-1351.

Blonigen, B.A., Piger, J.M., 2014. Determinants of foreign direct investment. Can. J. Econ. 47 (3), 775-812

Blonigen, B.A., Davies, R.B., Waddell, G.R., Naughton, H.T., 2007. FDI in space: spatial autoregressive relationships in foreign direct investment. Eur. Econ. Rev. 51 (5), $1303-1325$

Bodson, P., Peeters, D., 1975. Estimation of the coefficients of a linear regression in the presence of spatial autocorrelation. An application to a Belgian labour-demand function. Environ. Plan. A 7 (4), 455-472.

Buch, C.M., Lipponer, A., 2007. FDI versus exports: evidence from German banks. J. Bank. Financ. 31 (3), 805-826.

Chou, K.H., Chen, C.H., Mai, C.C., 2011. The impact of third-country effects and economic integration on China's outward FDI. Econ. Model. 28 (5), 2154-2163.

Claeys, P., Moreno, R., Suriñach, J., 2012. Debt, interest rates, and integration of financial markets. Econ. Model. 29 (1), 48-59.

Coughlin, C.C., Segev, E., 2000. Foreign direct investment in China: a spatial econometric study. World Econ. 23 (1), 1-23.

Dasgupta, A., 2004. Financial contagion through capital connections: a model of the origin and spread of bank panics. J. Eur. Econ. Assoc. 2 (6), 1049-1084.

Daude, C., Fratzscher, M., 2008. The pecking order of cross-border investment. J. Int. Econ. 74 (1), 94-119.

de Ménil, G., 1999. Real capital market integration in the EU: how far has it gone? What will the effect of the euro be? Econ. Policy 14 (28), 167-189.

Elliott, M., Golub, B., Jackson, M.O., 2014. Financial networks and contagion. Am. Econ. Rev. 104 (10), 3115-3153.

Felbermayr, G.J., Hiller, S., Sala, D., 2010. Does immigration boost per capita income? Econ. Lett. 107 (2), 177-179.

Fève, P., Pietrunti, M., 2016. Noisy fiscal policy. Eur. Econ. Rev. 85, 144-164.

Forbes, K.J., Rigobon, R., 2002. No contagion, only interdependence: measuring stock market comovements. J. Financ. 57 (5), 2223-2261.

George, A., Veeramani, P., 1994. On some results in fuzzy metric spaces. Fuzzy Sets Syst. 64 (3), 395-399.

Gómez-Puig, M., Sosvilla-Rivero, S. 2016. Causes and hazards of the euro area sovereign debt crisis: pure and fundamentals-based contagion. Econ. Model. 56 (August), $133-147$.

Gregori, V., Mascarell, J.A., Sapena, A., 2005. On completion of fuzzy quasi-metric spaces. Topol. Appl. 153 (5-6), 886-899.

Haaland, J.I., Wooton, I., 2007. Domestic labor markets and foreign direct investment. Rev. Int. Econ. 15 (3), 462-480.

Heid, B., Larch, M., 2012. Migration, trade and unemployment. Econ.: Open-Access, Open-Assess. E-J. 6 (4), 1-40.

Kleinert, J., Toubal, F., 2010. Gravity for FDI. Rev. Int. Econ. 18 (1), 1-13.

Leibrecht, M., Riedl, A., 2014. Modeling FDI based on a spatially augmented gravity model: evidence for central and eastern European countries. J. Int. Trade Econ. Dev. 23 (8), $1206-1237$.

Leitner, Y., 2005. Financial networks: contagion, commitment, and private sector bailouts. J. Financ. 60 (6), 2925-2953.

LeSage, J.P., Pace, R.K., 2008. Spatial econometric modeling of origin-destination flows. J. Reg. Sci. 48 (5), 941-967.

LeSage, J.P., Pace, R.K., 2009. Introduction to Spatial Econometrics. Chapman \& Hall/CRC, Boca Raton.

Márquez-Ramos, L., 2011. European accounting harmonization: consequences of IFRS adoption on trade in goods and foreign direct investments. Emerg. Markets Finan. Trade 47 (4), 42-57.

Portes, R., Rey, H., 2005. The determinants of cross-border equity flows. J. Int. Econ. 65 (2), 269-296.

Puy, D., 2016. Mutual funds flows and the geography of contagion. J. Int. Money Financ. 60, 73-93.

Sapena, A., 2001. A contribution to the study of fuzzy metric spaces. Appl. Gen. Topol. 2 (1), 63-75.

UNCTAD, 2008. World Investment Report 2008: Transnational Corporations and the Infrastructural Challenge. United Nations Publications, Geneva.

Weitzel, U., Kling, G., Gerritsen, D., 2014. Testing the fire-sale FDI hypothesis for the European financial crisis. J. Int. Money Financ. 49 (PB), 211-234.

${ }^{20}$ See Gregori et al. (2005). 